\title{
Factors Contributing to Marital Dissatisfaction and Divorce in the Military
}

\author{
Jennifer D. Lares ${ }^{1}$, Dr. Kruti Lehenbauer ${ }^{2}$ \\ ${ }^{1}$ DBA Student, University of the Incarnate Word, San Antonio, U.S.A., dicamill@student.uiwtx.edu \\ ${ }^{2}$ Associate Professor, University of the Incarnate Word, San Antonio, U.S.A., Lehenbau@uiwtx.edu
}

\begin{abstract}
Military members are no different than civilians in terms of the desires to have a life partner and have a satisfied marital life after marriage. However, the challenges faced by many military members and their families are different than those facing the civilian families by the sheer nature of their service. This study conducts an in-depth academic literature analysis regarding the impacts of the unique trials and tribulations that face military personnel on their marital dissatisfaction or dissolution. While an empirical hypothetical model to test whether factors such as length of deployment, number of deployments, posttraumatic stress disorder impact the military marital dissatisfaction is provided in this paper, there is no quantitative analysis conducted due to lack of access to relevant data.
\end{abstract}

KEYWORDS: Military, deployments, Post-Traumatic Stress Disorder (PTSD), divorce

\section{Introduction}

One of the often-overlooked aspects of military service is the impact it can potentially have on the personal relationships of an individual who is serving. This research paper presents a detailed literature review and analysis of the factors that contribute to military marital satisfaction, with particular focus on the propensity for divorces within military households. It is important to note that the term military marriage refers to any civil union between two people, at least one of whom is or has been an actively employed member of the military in the United States. We propose an empirical model that can be tested using data from the military databases compiled from sources such as Defense Manpower Data Collection Agency (DMDC) or other Federal data. Due to confidentiality reasons and the need for extensive IRB approvals to use this data, we are not performing any quantitative tests of the model. Instead, we are supplying a theoretical construct based upon factors affecting military health and marriage, such as length of deployment, number of deployments, and post-traumatic stress disorders among others that have been identified within the literature as being significant. The goal is to find and list the factors impacting personal relationships that will provide an outline for the Department of Defense (DOD) to increase the relevant support services to military personnel to improve their long run personal outcomes.

The DMDC in addition to other federal agencies such as the Veterans Affairs Office of Research and Development (ORD) collects a large amount of data on military personnel and their households. However, public or even requested access to this data is limited. While Federal workers or veterans do have access to some of that data, they are unable to share or delve into the carefully managed outcomes from these data for confidentiality reasons. This lack of access to data and confidentiality surrounding the military population and their information results in questions that continue to remain unanswered with respect to this unique population. Do military members have increased occurrences of failed marriages in comparison to their civilian counterparts, and if so, why? What causes divorce in military households? Are adequate support services available and are they being used appropriately? This paper attempts to identify some of the answers to these questions by reviewing the existing literature and then presenting a model that could be empirically tested, if data were to be made available.

\section{Literature Review}

Speculation about relationship challenges for the military labor force has been a subject of research interest gaining attention in recent times. Research surrounding various implications on the personal life of military personnel includes the effects of deployments (e.g. Balderrama-Durbin et al. 2017), mental 
health (e.g. Routon 2017), gender of the service member (e.g. Wang et al. 2015), and comparisons with civilian counterparts (e.g. London, Allen, \& Wilmoth 2013). Limited research exists prior to the military transition from required-service ("the draft") to an all-volunteer force in 1973. Additionally, studies relating to divorce rates among veterans and their root causes are scarce. This hypotheses essay will lay the groundwork for discovering the significant factors that influence marital satisfaction among military personnel, thereby setting the stage for recommended adjustments to current support services as well as suggesting the creation of new ones.

The military lifestyle is unique in its distinct demands. Service members are subjected to lengthy absences from home, constant relocations, rigid work expectations, and schedule inflexibility (Burrell, Adams, Durand \& Castro 2006; Drummet, Coleman \& Cable 2003). Deployments can put a strain on personal relationships because they can result in either PostTraumatic Stress Disorder (PTSD) or physical injuries or both. Theories to explain why military marriages fail abound but the data that researchers can gather remains limited and therefore renders the transition from theory to measurement a challenging task (Karney \& Crown 2011; Negrusa, Negrusa \& Hosek 2014). The lack of homogeneity in support services that are offered to various military branches prevents existing research from being generalizable.

The studies that do incorporate all U.S. military branches, namely Navy, Marine Corps, Army, Air Force, and Coast Guard, while benefitting from inclusivity, lack a longitudinal perspective. An exception to this general observation is the Karney, Loughran \& Pollard (2012) study that examines 10 years of military records varying by branch and provides one of the most indepth views into military marital trends. This section is divided into the key sub-sections based upon the type of existing literature that examines specific factors of military marital satisfaction, or the lack thereof.

\section{A. Military vs. Civilian Divorce Rates}

It is reasonable to assume that military marriages are more susceptible to end in divorce than civilian unions because the fundamental dynamics of work are different between military and civilian labor force. As mentioned earlier, military marriages are often subjected to lengthy periods of separation, lack of immediate access to each other's location, frequent transfers, and a distinct set of work priorities and emergent situations. Two hypotheses appear that offer an explanation for failed military marriages from the literature, (1) the stress hypothesis and (2) the selection hypothesis. According to the stress hypothesis, extreme demands are made on service members resulting in divorce, while the selection hypothesis claims that the population recruited for military service are predisposed or "high risk" candidates for divorce to begin with (Hogan \& Seifert, 2010).

The question of whether divorce occurs more frequently in the military or civilian population was explored in a study by Karney \& Crown (2007) who conducted a cross sectional study spanning a 10-year period, utilizing DMDC data from 2007. Findings reveal a lack of support for the stress hypothesis for all military branches except for Air Force members who had been deployed for long periods. The reverse held true for other branches, indicating the more days members were deployed the less likely they were to become divorced. This could be a result of a different caliber of support services amongst the other branches but there is no substantiation provided for this question. While stress may cause the emergence of traits not otherwise shown by people, which could relate to the feasibility of the stress hypothesis, data for that conclusion is inadequate and requires further study. Karney \& Crown (2007) concludes that while the stress hypothesis can explain some of the impacts of military service on marriage, it is not consistently proven to be significant across various studies.

Military members tend to marry younger and earlier than their civilian counterparts and this could be a result of the enticing compensations and benefits provided to married military members, without which those marriages might not have occurred in the first place (Karney \& Crown 2007). According to Military Advantage (2019), married service members are paid an increased rate of Basic Housing Allowance (BAH), are eligible for Basic Allowance for Subsistence (BAS) and can live off-base. Marriage also allows the military member to continue a relationship with a civilian 
regardless of where the member is stationed. Moreover spouses, whether military or civilian, can go with the service member to the various duty stations over the course of their military career.

A follow up study compares divorces in the military and the civilian populations across two time periods, pre-conflict, from 1998 to 2001 and post-onset of hostilities from 2002 to 2005. The results show that there are no significant differences between military and civilian divorce rates, even though the general trend of divorces in the military is increasing between the two time periods studied (Karney et al. 2012). The study confirms the earlier conclusions that military males tend to marry earlier as compared to civilian males. However, identifying if military members marry sooner than civilians and if divorce is a less preferred outcome as a result of differentiated benefits available to the two groups, or whether differentiated benefits are available because of earlier marriage and discouraging divorce within military, makes it challenging to obtain clear conclusions (Hogan \& Seifert 2010; Karney et al. 2012).

It is tempting to presume that once the military member returns to the civilian sector, the stressors specific to service are removed and therefore improves the marital relationship. However, this is not the case because the effects from the time previously served may create unique-tomilitary difficulties such as long-term service-related physical and mental health problems, disruptions in educational attainment, and traditional career options as compared to civilians (London, Allen, \& Wilmoth 2013).

Routon (2017) is a longitudinal study that examines military and civilian individuals within the same age cohorts to test for the selection hypothesis and concludes that there is in fact a relationship between military service and divorce (p. 353). The study finds that dissolution of marriage typically occurs within a two-year time span following separation from the military and the return of the member to the civilian sector (p. 353). Routon (2017) suggests that while the selection hypothesis appears to be valid prima facie, further studies on marriage, marital stability, and the choice to volunteer in the armed forces would be necessary to confirm its significance and measure the impact of self-selection on military marital outcomes as compared to civilian marital outcomes.

\section{B. Deployment}

With the departure from a military-in-peacetime, following September 11, 2001, deployments to support the War on Terror began. While deployment does not always involve exposure to combat, it is often a stressful period of separation from family (Karney \& Crown 2007). Interestingly, divorce rates within deployed members between 2002 to 2005 were lower than those for non-deploying military personnel during that same time period (Karney et al. 2012). It is possible that the expectations for those married prior to the Iraq/Afghanistan conflicts may have been starkly different from the experienced reality as members deployed to those locations. The threat of deployment and constant readiness service members are expected to exhibit, can be a constant source of stress within the relationship. Problems posed by long periods of separation may include infidelity, reintegration challenges, and communication or intimacy issues (Karney et al. 2012). Members involved in combat situations may return with either mental or physical health effects or both. These might also have different implications by gender of the military member. For instance, female service members cited deployment as the primary contributing factor to dissolution in their marriages (Rossiter \& Chandler 2013; Negrusa, Negrusa \& Hosek 2014).

Prior research examining Army reservists found that intimacy and closeness can be difficult to maintain while apart, even though technology has allowed for significant improvement for modern military couples as compared to their counterparts who were serving during the Vietnam Era (Karakurt et al. 2013). Increased communication with family and spouse results in less distraction for the service member and couples that are already in marital turmoil often limit communication, which compounds the compromising of a deployed member's focus and safety (Carter et al. 2015). Another risk to a couple that is physically separated as a result of deployment is often noted to be infidelity. A qualitative study exploring the impacts of infidelity during a yearlong deployment concludes that infidelity often occurs as a result of pre-existing influences among couples that are already dealing with a distressed relationship (Balderrama-Durbin et al. 2017). 
Thus, instead of being the cause for marital failure, infidelity was more of a symptom of a failing relationship. And while deployment could create a fertile environment for infidelity, it is most likely not the cause of the infidelity to begin with.

A longitudinal study exploring the impact of deployment on marriage using military data for the years 1999 to 2008 also concludes that those married prior to September 11, 2001 exhibited increased "marital shock" as compared to those that were married after the War on Terror was launched (Negrusa, Negrusa \& Hosek 2014). Contrary to previous findings suggesting that deployment only marginally effects divorce rates in the military (Karney et al. 2012), the importance of cumulative time deployed and its impact on increasing the risks of divorce is underlined by Negrusa et al. (2014) regardless of whether the deployment was hazardous duty or not.

In a unique take on military marriage studies, an earlier study by Pincus et al. (2001) divided the deployment process into five stages that culminate into an emotional cycle: pre-deployment, deployment, sustainment, re-deployment, and post-deployment. Each stage had its own unique period of time and challenges, with post-deployment and the return of the service member considered as the most important stage. A later study by Sheppard, Malatras, Weil, \& Israel (2010) elaborates on these stages and concludes that marital separation and eventual divorce can be associated with deployment based upon the trials a military member and spouse have to endure during deployment. This is also indicative of the understanding that an intrinsically strong marriage can survive these tribulations, albeit a civilian marriage would not necessarily have to deal with these trials in the first place, making it all the more difficult to separate the causes of divorce and the effects of deployment a military relationship.

\section{Mental Health}

The subject of mental health has received increased attention in recent years, as the frequency of traumatic brain injuries has increased and an understanding of health issues such as the long-term impacts of Post-Traumatic Stress Disorder (PTSD) has improved. Almost one in five members who served in Operation Iraqi Freedom (OIF) or Enduring Freedom (OEF) is dealing with PTSD in one form or another every year (U.S. Department of Veterans Affairs, 2019). The stigma associated to reporting mental health conditions such as PTSD could mean that these numbers are underestimating the reality, because the resulting repercussions on career outcomes might prevent military members from seeking help and a proper diagnosis in a timely manner. While injuries in any sense can cause challenges within a relationship, the invisible ailments that affect the mind can be especially challenging. It is not uncommon for spouses of military members to struggle with understanding the symptoms and behaviors of the service members. A study by Kar \& O'Leary (2013) seeks to find the link between PTSD and intimate partner violence (IPV) by hypothesizing that service members with "unhealthy attachment styles and poor emotional coping skills (as evidenced through use of IPV)" might be less equipped to handle trauma experiences and are likely to develop PTSD at higher rates than their counterparts in the military. Military service members are screened prior to deployments, though there may be an inquiry currently being omitted which could aide in the detection of those with underdeveloped coping skills prior to being deployed and thereby eliminating those at high-risk to develop PTSD from being exposed to unusual trauma. Upon return from deployment, those that are suffering from early or fully-onset PTSD might show a type of "emotional numbing", which can negatively impact relationship intimacy (Kar \& O'Leary 2013). The corresponding decline in emotional closeness and the potential for self-harm or IPV, if left untreated, could result in decreasing marital satisfaction and eventual separation or divorce, depending on the severity of the symptoms.

A similar study investigating PTSD and IPV seeks to compare and contrast the characteristics of veterans who exhibit IPV and those that do not, while receiving treatment for PTSD (Gerlock et al. 2016). The variables in this study were PTSD severity, witnessing of inter-parental IPV as a child, substance use/abuse prior to service and post-return from deployment, mutuality, and other demographic characteristics to control for variation within different groups. The results indicate that the only shared trait between the two groups was mutuality and IPV peaked in severity within the first two years following deployment in the group of veterans who exhibited a propensity towards 
IPV (Gerlock et al. 2016). Given that mutuality was a significant factor, Gerlock et al. (2016) advocate PTSD treatment options that include the spouse, confirming a previous recommendation made by Miller et al. (2013).

PTSD and other depressive symptoms associated with a bad mental health situation are consistently found to be decrease marital satisfaction for both the military member and their spouse (Foran, Wright \& Wood 2013; Bergmann, et al. 2014). Marital satisfaction and communication suffer when military personnel engage in PTSD related behavior triggered by exposure to danger and constant threat to life during deployment even after they return to civilian life. They could react either by withdrawing completely or being overly-sensitive or paranoid regarding external factors including focusing exclusively on the negative aspects of their relationships (Foran, Wright \& Wood 2013). Pre-existing unhappiness in a marriage can be worsened by the presence of PTSD, materializing in IPV, disengagement, or the attention the individual and illness require which further detracts from the marital focus (Foran et al. 2013, 921).

The significance of trauma and attachment issues was explored by studying conflict discussions between trauma-exposed veterans and their intimate partners by Miller et al. (2013). In this qualitative study, 287 couples were observed in order to determine the manner in which PTSD symptoms influence the nature and quality of their communication. These type of one-on-one observations found that more hostility and distress is exhibited by the spouses of the military members during the discussions, which lends credibility to the notion that PTSD impacts communication between couples, creates dissatisfaction in the relationship, and over time could lead to a deterioration in the quality of the relationship completely, if left untreated (Miller et al. 2013). This echoes what a previous study focusing on how the perceptions of the spouse impact the quality of the relationship in a military marriage (Renshaw et al, 2008). Perceived combat exposure by the spouse and level of understanding influenced marital satisfaction among those struggling with PTSD. If there was minimal combat exposure but the service member reported high levels of PTSD, or if the member had high levels of exposure but demonstrated low levels of PTSD, the spouse was dissatisfied because non-military spouses associate the exposure to combat with expected level of PTSD, which might be a perceptional fallacy, at best (Renshaw et al. 2008).

\section{Gender Implications}

In 2016, the U.S. military consisted of 204,628 female service members or $15.9 \%$ of the total force which represents a significant growth in number of female service members as compared to the past (Department of Defense 2016). Although women are the minority in the military, they are more likely to be married, especially to a fellow military member (Karney \& Crown 2007; Lietz, Stromwall, \& Carlson 2013) and have higher divorce rates than military males (Wang et al. 2015), with those married to civilians most likely to experience failed marriages (Karney \& Crown 2007). The opposite holds true for males in service, whose marriages to civilians are the most successful while also the most plentiful (Karney \& Crown 2007). The divorce rate in 2010 among military personnel was $7.8 \%$ for females as compared to $3 \%$ for males and the reason most cited as the cause of divorce by female participants in the Rossiter \& Chandler (2013) study was deployment, followed by PTSD, military sexual trauma, tours of duty, spousal infidelity, and reintegration complications. Negrusa, Negrusa \& Hosek (2014) also found deployment to be particularly harder on female military members in their study, as mentioned earlier.

While female military members indubitably appear to be at higher risk for divorce within the military population, the lack of insight into the female experience leaves questions as to causes of this disparity. Could the additional role of motherhood be applicable for those with children? Have the military fully embraced women within the armed forces and considered the various aspects in which gender may be significant? Unfortunately, not much literature exists on this topic and as mentioned at the beginning of this paper, limited access to data and service member information, makes it even harder to identify the causes of disproportionately higher failed marriages in the female population of the military. 


\section{Results from the Literature Analysis}

The military is a complex organization with a long history, proud traditions, and the propensity towards constant change. In recent times the change in the composition of the military and its diversity is even more pronounced than earlier as the percentage of females fighting alongside men is increasing every year, same-sex couples are being accepted and acknowledged, and the need to keep a state of constant readiness as technology and wartime evolve. However, changes bring new needs and thereby new opportunities to serve those that serve in a manner that enhances their quality of life. Research about the personal outcomes and relationships of the military members has been limited by a lack of access to data and information. Longitudinal studies are constrained with data limited to personnel records supplying superficial information. Qualitative studies have been conducted heterogeneously with focus on different branches without any way to connect the results meaningfully across the five branches of the military, thereby preventing generalizability and supplying conclusive results.

The key findings from the literature discussed above indicate that the benefits and incentive structure of the military could inadvertently increase the likelihood of earlier marriage and even reduce the likelihood of divorce in the long run, but there is no available quantitative analysis that estimates this relationship statistically. The selection hypothesis that pre-existing risk results in failure of the marriage independently of the military aspect of the relationship has not been tested conclusively in the literature. Physical or mental illness can impede career progression resulting in an under reporting of conditions like PTSD in active duty personnel. Studies involving veterans versus active duty members are easier to conduct, learning more about the effectiveness of the screening process and areas for improvement may alleviate deploying unfit members to begin with and avoiding the potential damage upon their return. Treatment options that incorporate the family unit as a whole, to include the spouse and children if pertinent, may increase overall understanding of the illness and cultivate effective communication between the couple. Reintegration from lengthy separations is a challenge for the entire family, and an area where improvement could be made for gradual immersion. Despite multiple efforts, the unique experience of female personnel and their marital satisfaction remains shrouded in even more mystery than their counterparts. Part of the reason for this gap is again, the lack of access to relevant data and the inability to collect more qualitative data directly.

\section{Proposed Empirical Model}

Based on the findings regarding military divorce rates from the literature, we hypothesize that factors such as deployment and PTSD contribute to increasing marital dissatisfaction, while age and gender of the military member matter in terms of negative marital outcomes. We propose a research design that uses married and divorced couples with at least one spouse being a member of the military as the unit of analysis. In the model, marital dissatisfaction would be the primary dependent variable. The challenge with measuring marital dissatisfaction is in the way it can be defined while collecting data. Thus, we can use the proxy of using marital status to represent dissatisfaction. If the self-reported marital status is divorced or separated legally, it is indicative of marital dissatisfaction.

The key independent variables to include are active duty measure (binary variable), separation from family measures (number of deployments, total tours of duty), number of years of marriage prior to military service, number of years of marriage post military service (if not active duty), total length of marriage in years, PTSD measures (binary variable representing presence of PTSD, ranked variable representing level of PTSD), number and type of physical injuries during active duty, access and utilization of reintegration services post active duty, gender of the military member, gender of the spouse, and other demographic variables. Thus, our general research model can be represented as follows:

Marital status $=f$ (active, deploy, tours, years married, PTSD, injuries, reintegrate, gender, demo)

If an exploratory sequential mixed methods design is implemented, the first estimates of this model can be obtained quantitatively by using cross-sectional or longitudinal data from among all married military members, both active duty or retired, in the five branches. These results would indicate which of the key 
identified variables are significant indicators of marital dissatisfaction in our military families, and therefore which ones require more in-depth analysis. Once these results are obtained, depending upon the type of data available either a more complex quantitative analysis approach can be implemented to predict the probabilities of marital dissatisfaction. Given the difficulties that previous researchers have faced, as well as the challenges we have faced in trying to access and use data for this exercise, we are unsure what the results of regression model are likely to be and therefore initial estimates obtained by using cross-sectional data from either the DMDC, VAORD, or the DOD, for all five branches of the military, might still be a pipedream.

On the other hand, a mixed-methods approach that collects primary data by reaching out to married, divorced or separated military couples through surveys and interviews can provide insights into the workings and unique challenges of a military marriage. In the first, quantitative phase of the study, the data based upon our research model given above would be collected from surveys completed by military members who are currently serving or have served in various geographic areas administered by their local support service providers. The distribution would equitably include the Air Force, Navy, Marine Corps, Army, and Coast Guard personnel of all races, ethnicities, and genders. Those who are utilizing support services for mental health or marital counseling services will have reasons for doing so, and the benefits derived from the research findings could be deemed valuable, thereby encouraging the intermediate organizations to invest in the delivery of the survey instrument. Once the data is collected, estimates can be obtained as described earlier using a regression analysis approach and the significant variables can be identified within the military families. Once the identification of which type of military members are most effected are made, the next phase can be implemented. The second, qualitative phase would be a series of interviews that would provide key insights into the specific factors that influence marital dissatisfaction in a military relationship. While the access to active duty personnel is more challenging as compared to reaching out to those who have completed their military service, having the information while the member is in the throes of the experience would prove beneficial for clarity as well as highlight current processes in place that negatively impact the military marriage. Discovering the existence and influence of stigmas and barriers to seeking aide would be identified during the stages when it could influence change successfully. Additionally, the spousal perspectives would be directly included in the interview portion of the study, thereby giving the importance of the hypothesized factors not only on the military member but also on their household as a unit.

\section{Conclusions}

There is much to be learned about military marriage and its implications. Conclusions from the literature regarding the predisposition of military marriages for failure are often conflicting at worst and uncertain at best. Since support services vary, each branch of service needs to be examined as its own entity in order to obtain results that are specific to its needs. While it is easy to discuss and hypothesize what data from the military show in quantitative and qualitative terms, if it were available, some of the simplest solutions for increasing longevity of military marriages might be as easy as asking the right questions and paying closer attention to the usefulness and utilization of existing support services.

For instance, identifying what portion of military services are voluntary and which are mandatory can make an impact on a married member's personal life. Effective pre-marital counseling is likely to help with improving marital satisfaction by setting the correct expectations for a military marriage. The various support services available to military members and veterans need to be tested often for effectiveness in lowering marital dissatisfaction and other issues among members and their households. It would also help to identify whether adequate support is being offered to females and same-sex couples in the military, given the changing dynamics of the composition of military members in all five branches. Longitudinal data on mental health and marital satisfaction for military members can offer beneficial insights into the long-term impacts of military service on personal relationships. While the Department of Defense and Department of Veterans Affairs are separate entities, collaborative approaches based on post-service treatment being sought out may advance care given while members are serving in an active capacity. 


\section{References}

Balderrama-Durbin, C., Stanton, K., Snyder, D., Cigrang, J., Talcott, G., Smith Slep, A.,Heyman, R. Cassidy, D., and Fiese, B. H. 2017. "The Risk for Marital Infidelity Across a Year-Long Deployment." Journal of Family Psychology 31(5): 629-634. Doi: http://dx.doi.org/10.1037/fam0000281.

Bergmann, J. S., Renshaw, K. D., Allen, E. S., Markman, H. J., and Stanley, S. M. 2014. "Meaningfulness of Service and Marital Satisfaction in Army Couples." Journal of Family Psychology 28(5): 701-706. Doi:http://dx.doi.org.uiwtx.idm.oclc.org/10.1037/fam0000013.

Burrell, L., Adams, G., Durand, D., and Castro, C. 2006. "The Impact of Military Lifestyle Demands on Well-Being, Army, and Family Outcomes.” Armed Forces and Society 33(1): 43-58. Doi:10.1177/000276206288804.

Carter, S. P., Allen, E. S., Loew, B., Osborne, L., Stanley, S. M., and Markman, H. J. 2015. "Distraction During Deployment: Marital Relationship Associations with Spillover for Deployed Army Soldier." Military Psychology (American Psychological Association) 27(2): 108-114. Doi:10.1037/mil0000067

Department of Defense. 2016. "2016 Demographics Report.” Accessed March 5, 2019. https://download.militaryonesource.mil/12038/MOS/Reports/2016-Demographics-Report.pdf.

Drummet, A., Coleman, M. and Cable, S. 2003. "Military Families Under Stress: Implications for Family Life Education." Family Relations 52(3): 279-287.

Foran, H., Wright, K., and Wood, M. 2013. "Do Combat Exposure and Post-Deployment Mental Health Influence Intent to Divorce?" Journal of Social and Clinical Psychology 32(9): 917-938. Doi: 10.1521/jscp.2013.32.9.917.

Gerlock, A. A., Szarka, J. G., Cox, K. and Harel, O. 2016. "Comparing Intimately Violent to Non-violent Veterans in Treatment for Posttraumatic Stress Disorder.” Journal of Family Violence 31(6): 667-678. Doi:10.1007/s10896016-9814-2.

Hogan, P., and Furst Seifert, R. 2010. "Marriage and the Military: Evidence That Those Who Serve Marry Earlier and Divorce Earlier." Armed Forces \& Society 36(3): 420-438. Doi:10.1177/0095327X09351228

Kar, H., and O'Leary, K. 2013. "Emotional Intimacy Mediates the Relationship Between Posttraumatic Stress Disorder and Intimate Partner Violence Perpetration in OEF/OIF/OND Veterans.” Violence and Victims, 28(5): 790-803. Doi: http://dx.doi.org/10.1891/0886-6708.

Karakurt, G., Christiansen, A., Wadsworth, S., and Weiss, H. 2013. "Romantic Relationships Following Wartime Deployment.” Journal of Family Issues 34(11): 1427-1451. Doi: 10.1177/0192513X12470799

Karney B.R., and Crown J.S. 2007. "Families Under Stress: An Assessment of Data, Theory, and Research on Marriage and Divorce in the Military." RAND Corporation.

Karney, B. R., Loughran, D. S., and Pollard, M. S. 2012. "Comparing Marital Status and Divorce Status in Civilian and Military Populations.” Journal of Family Issues 33(12): 1572-1594. Doi:10.177/0192513X12439690.

Lietz, C., Stromwall, L., and Carlson, B. 2013. "Women Service Members and Family Reintegration." Families in Society, 94(3), 186-193. Doi: 10.1606/1044-3894.4314.

London, A., Allen, E., and Wilmoth, J. 2013. "Veteran Status, Extramarital Sex, and Divorce: Findings from the 1992 National Health and Social Life Survey." Journal of Family Issues 34(11): 1452-1473. Doi: 10.1177/0192513X12460510.

Military Advantage. 2019. "Military Spouse and Family Benefits.” Accessed March 1, 2019. https://www.military.com/spouse/military-benefits/military-spouse-and-family-benefits-101.html.

Miller, M. W., Wolf, E. J., Reardon, A. F., Harrington, K. M., Ryabchenko, K., Castillo, D., Freund, R., and Heyman, R. E. 2013. "PTSD and Conflict Behavior Between Veterans and Their Intimate Partners." Journal of anxiety disorders 27(2): 240-51. Doi: 10.1016/j.janxdis.2013.02.005.

Negrusa, S., Negrusa, B., and Hosek, J. 2014. “Gone to War: Have Deployments Increased Divorces?” Journal of Population Economics 27(2): 473-496. Doi: 10.1007/s00148-013-0485-5.

Pincus, S. H., House, R., Christenson, J., and Adler, L. E. 2001. “The Emotional Cycle of Deployment: A Military Family Perspective." U.S. Army Medical Department Journal 4/5/6: 15-23.

Renshaw, K., Rodrigues, C., and Jones, D. 2008. "Psychological Symptoms and Marital Satisfaction in Spouses of Operation Iraqi Freedom Veterans: Relationships with Spouses' Perceptions of Veterans' Experiences and Symptoms." Journal of Family Psychology 22(4): 586-594. Doi: 10.1037/0893-3200.22.3.586.

Rossiter, A.G., and Chandler, R. 2013. "Women Veterans and Divorce: What Are the Contributing Factors?" Nurse Leader 11(5): 51-53.

Routon, P. 2017. "Military Service and Marital Dissolution: A Trajectory Analysis." Review of Economics of the Household 15(1): 335-355. Doi:10.1007/s11150-016-9323-3.

Sheppard, S.C., Malatras, J.W., and Israel, A. C. 2010. "The Impact of Deployment on U.S. Military Families." American Psychologist 65(6): 599-609. Doi: 10.1037/a0020332.

U.S. Department of Veterans Affairs. 2018. (September 24). "How Common is PTSD in Veterans?" Accessed March 6, 2019. https://www.ptsd.va.gov/understand/common/common_veterans.asp.

Wang, L., Seelig, A., Wadsworth, S., McMaster, H., Alcaraz, J., and Crum-Cianflone, N. 2015. "Associations of Military Divorce with Mental, Behavioral, and Physical Health Outcomes." BMC Psychiatry 15(1): 1-12. Doi: 10.1186/s12888-015-0517-7. 